\title{
La escritura de Ignacio Torres Giraldo. El aprendizaje de un autodidacta*
}

Artículo recibido: 10-12-2015 | Artículo modificado: 20-2-2016 | Artículo aceptado: 30-03-2016

\section{Alfonso Rubio}

Doctor en Sistemas de Información y Documentación, y Licenciado en Filología Hispánica por la Universidad de Zaragoza (España). Profesor asociado del Departamento de Historia de la Universidad del Valle (Colombia). Miembro del Grupo de Investigación Nación-CulturaMemoria, en el que desarrolla la línea de investigación en Estudios de Cultura Escrita. Entre sus publicaciones recientes se encuentran el libro Los escribanos de la Villa de Medellín, 16751819. Las representaciones de un oficio en la escritura de su archivo (Medellín: Universidad de Antioquia, 2015); y los artículos "Los tratados de práctica notarial en las bibliotecas de escribanos neogranadinos del siglo XVIII", Historia y memoria, 13 (2016), 19-46; y “La historia del libro y de la lectura en Colombia. Un balance historiográfico”, ICS, 34 (2016) 1126. Correo electrónico: alfonso.rubio@correounivalle.edu.co

Referencia para citar este artículo: Rubio, Alfonso. "La escritura de Ignacio Torres Giraldo. El aprendizaje de un autodidacta". Historia y Espacio 47 (2016): 123-141.

\footnotetext{
* Artículo Tipo 2: de reflexión según clasificación de Colciencias. Este ensayo es producto de la investigación particular llevada a cabo por el autor en el Fondo Documental Ignacio Torres Giraldo (FDITG) de la Biblioteca Central de la Universidad del Valle (Cali, Colombia). No contó con financiación.
} 


\section{La escritura de Ignacio Torres Giraldo.}

\section{El aprendizaje de un autodidacta}

Resumen: A partir del análisis de las obras Recuerdos de infancia y Anecdotario, de Ignacio Torres Giraldo (1893-1968), este ensayo indaga sobre el significado de su escritura autobiográfica y sus prácticas de lectura y escritura en tanto formas de autodidactismo. Se intenta mostrar cómo estos aspectos, ligados a su quehacer como figura política, líder sindical, historiador, escritor y periodista, favorecieron la definición y el perfeccionamiento de su ideología política, en un contexto histórico-social marcado por la importancia que adquiere la relación directa y comprometida con la cultura popular para obtener y crear conocimiento científico.

Palabras clave. Ignacio Torres Giraldo, escritura, lectura, tipografías, periodismo, sindicalismo, siglo XX, Colombia.

\section{The Writing of Ignacio TorresGiraldo.}

\section{The Making of a Self-taught}

Abstract: Based in two literary works of the Colombian historian and syndicalist Ignacio Torres Giraldo (Recuerdos de infancia and Anecdotario) we discuss the meaning of his autobiographical writings and examine his impressive record as a self-taught reader and writer, a record always put at the service of his ideological training. It tries to show how these aspects, linked to his work as a political figure, union leader, historian, writer and journalist, favored the definition and enhancement of their political ideology, in a historical and social context marked by the importance acquired the direct relationship and committed to popular culture for and create scientific knowledge.

Key Words: Ignacio Torres Giraldo, Writing, Reading, Typography, Syndicalism, Journalism, 20th Century, Colombia.

\section{A escritura de Ignacio Torres Giraldo.}

\section{A aprendizagem de um autodidata}

Resumo: A partir da análise das obras Recuerdos de infancia e Anecdotario do escritor Ignacio Torres Giraldo (1893 - 1968), este ensaio indaga sobre o significado de sua escritura autobiográfica e suas práticas de leitura e escritura enquanto que formas de autodidatismo. Tenta-se mostrar como esses aspectos, ligados a seu desempenho como figura política, dirigente sindical, historiador, escritor e jornalista, permitiram a definição e aperfeiçoamento de sua ideologia política, em um contexto histórico-social marcado pela importância da relação direta e comprometida com a cultura popular para criar conhecimento cientifico.

Palavras-chave: Ignacio Torres Giraldo, escritura, leitura, tipografia, sindicalismo, século XX, Colômbia. 
Mi pasión ha sido siempre leer y escribir, cosas que he hecho cada vez que la lucha por el pan y las ideas me lo ha permitido.

Ignacio Torre Giraldo Anecdotario

\section{Introducción}

En 1974, en el apartado denominado "Guía de libros" del diario El Tiempo, María Mercedes Carranza reseñó Los inconformes, la obra del colombiano Ignacio Torres Giraldo (1893-1968) que la Editorial Margen Izquierdo había publicado en la ciudad de Bogotá. La obra, dice la reseña, "permite hacerse una idea de la variada gama de dificultades y contradicciones que rodearon la época en que comenzó a manifestarse el socialismo en Colombia”. En este sentido, la historia de Torres Giraldo, uno de los fundadores en 1926 del Partido Socialista Revolucionario que en 1930 dio origen al Partido Comunista, es un valioso documento, cuya trascendencia "aumenta a medida que se acerca a la exposición y análisis de los hechos de su época, en los cuales tuvo participación directa [...], un acerbo de datos dados de primera mano definitivos para elaborar la historia del sindicalismo en el país"1.

Esa participación directa y comprometida en los hechos de su época es lo que hace que sus textos contengan un alto nivel de subjetividad, la mayor crítica que se hace a su trabajo desde la rigurosidad científica necesaria para abordar la historia o la sociología de la realidad colombiana. Pero la información que ofrece un testigo directo de los hechos políticos que le afectan, desde la observación y el análisis personal, es tan válida como las valoraciones subjetivas de los políticos militantes u oficiantes y las que buscan la objetividad desde las ciencias sociales².

La historia que envuelve a Torres Giraldo está contada por alguien que participa en ella, él se siente parte de una época cuyos hechos relata como si su propia figura fuera un documento de la historia. Ciertamente lo es y como escritor, es consciente de ello. En su escritura vivencial, autobiográfica, se encuentra a gusto y por ello, dentro de una vasta obra que todavía no ha sido dada a conocer en su totalidad, donde aparecen géneros literarios como el ensayo, la novela, la narración histórica, el

1 María Mercedes Carranza, "Guía de libros: Los inconformes”, El Tiempo, Bogotá, 21 de enero, 1974.

2 Sobre el problema de la subjetividad en la investigación y la escritura de la historia enlazadas a un lugar de producción socioeconómica, política y cultural, Michel de Certeau, La escritura de la historia (México DF: Universidad Iberoamericana/Instituto Tecnológico y de Estudios superiores de Occidente, 2010). 
comentario económico y sociológico, o la crónica periodística, es frecuente lo esencialmente biográfico: Cincuenta meses en Moscú; María Cano, mujer rebelde; Anecdotario y Recuerdos de infancia 3 .

Lo biográfico inscrito dentro de lugares y contextos históricos de enunciación de los cuales la historiografía colombiana ha dado buena cuenta. Ignacio Torres Giraldo es partícipe de un proceso social por el que el obrerismo, bajo la influencia de ideologías como el socialismo y el liberalismo progresista alcanzó importantes reivindicaciones laborales y sociales. Recuerdos de infancia y Anecdotario se escriben desde esa perspectiva, pero el interés de este ensayo no es el de detenerse en los hechos políticos o económicos que transformaron la sociedad colombina en las primeras décadas del siglo XX y envolvieron la vida del líder sindical, sino el de analizar su escritura autobiográfica, que muestra el aprendizaje autodidacta de su actividad letrada y tipográfica ${ }^{4}$.

\section{La lectura de un autodidacta en su formación ideológica}

El original del Anecdotario aparece fechado en el año de 1957 y posteriormente, al parecer en 1965, el autor añade un último apartado que brevemente referencia hechos de los años de 1963, 1964 y 1965. Fue editada por primera vez en el 2004 por el Programa Editorial de la Universidad del Valle. Recuerdos de infancia permanecía inédita hasta abril de 2016, cuando el mismo Programa Editorial presentó juntas ambas obras por su similitud en tono y contenido describiendo un paisaje social, familiar y cultural especialmente colombiano. Los Recuerdos fueron escritos entre 1946 y 1950 , nos lo dice el propio autor en una nota de 1965 introductoria a los textos mecanografiados originales de esta obra que hace parte del Archivo Personal de Ignacio Torres Giraldo, donado por su familia en el año de 2008 a la Universidad del Valle, en cuya Biblioteca Central se conservan. En dicha nota también nos habla del interés que estos apuntes memorísticos poseen si se les mira "como testimonio de los destrozos que hacía la guerra del 99”. En otras palabras, se trata de cuadros de dolor personal a los que se invita a mirar desde un sentido colectivo.

Se trata de recuerdos y anécdotas de breves episodios donde la reflexión autobiográfica se apropia de la escritura como acto y necesidad de una introspección solitaria para revivir un tiempo de

3 Para una semblanza de Ignacio Torres Giraldo y un recorrido sintético por su obra publicada e inédita, Alfonso Rubio y Viviana Arce, Inventario general. Fondo documental Ignacio Torres Giraldo (Cali: Programa editorial, 2014), 21-39.

4 Sobre el contexto político que atraviesa la actividad sindical de Ignacio Torres Giraldo y especialmente la prensa obrera y popular de las tres primeras décadas del siglo XX colombiano, Luz Ángela Núñez Espinel, El obrero ilustrado. Prensa obrera y popular en Colombia, 1909-1929 (Bogotá: Universidad de los Andes/ Facultad de Ciencias Sociales-Ceso/ Departamento de Historia, 2009). Sobre distintos géneros de literatura memorialista (correspondencia, diarios, memorias, autobiografías), Paula Sibilia, La intimidad como espectáculo (México DF: Fondo de Cultura Económica, 2008).

5 Ignacio Torres Giraldo, "Nota previa” al original de Recuerdos de infancia, 1965, 1. FITG, 4/8-A. El apartado titulado "Un retrato descriptivo" está escrito el 7 de febrero de 1962 y aparece encabezado por la indicación que dice "Para intercalar”. Cuando se escribe este ensayo todavía la edición conjunta mencionada (Recuerdos de infancia y anecdotario. Cali: Programa Editorial de la Universidad del Valle, 2016) no se había publicado. 
guerras, de evidentes injusticias sociales; para recordar sucesos extraordinarios, personales y políticos, que fueron marcados por el devenir de un periodo histórico concreto, por lo que su reflexión autobiográfica no se detiene sólo en lo más íntimo de él, al contrario, la exterioriza para pensarla y hacerla “cuestión social”. El “pensamiento escrito”, como dijo Pedro María Torres (1900-1995), un obrero antioqueño escritor de un diario personal durante los años de 1940 a 1992, "es fiel reflejo de la personalidad de quien lo escribe”6. No son hechos insignificantes los que Torres Giraldo ha seleccionado de entre su memoria para dar a conocer a los demás, pues el ejercicio reflexivo que hace de ellos por medio de la palabra escrita demuestra que han sido momentos que marcaron su personalidad, como en algunas ocasiones, explícitamente, el propio autor nos lo hace saber. Desde su niñez hasta el año de 1965, desfilan en estas evocaciones personajes (familiares, amigos, políticos), hechos históricos y escenarios colombianos diversos que hasta entonces, hasta el momento de su escritura, permanecían ocultos en su recóndita intimidad.

A través de la reconstrucción textual de estos episodios, Torres Giraldo como autor, se representa así mismo, se autoexamina, al tiempo que estructura su propia historia bajo una superestructura mayor que es la historia de la sociedad. Recupera su pasado por medio de recreaciones, a veces aisladas temáticamente, más o menos distantes en el tiempo, pero siempre conectadas por momentos de agitación política, para hacerlo común dentro de un proceso histórico. Al tiempo que escribe, define su identidad como persona, pero también la personalidad, en la medida de lo posible, del país de su tiempo. Como suele suceder con los “diarios”, estas páginas ven la luz cuando la vida de quien las ha escrito se ha extinguido. Ya no está su autor entre quienes ahora podemos leerlas para preguntarle por los hechos concretos que describe, pero la mejor defensa de sus confesiones no es su propia voz, sino la voz, frente a las "gentes petrificadas", de quienes llamó "espíritus en evolución”7

La escritura es también un acto consciente de permanecer en todos. En 1965, cuando Torres Giraldo revisa el original de Recuerdos de infancia, no encuentra en ellos "nada que deba corregir [...] substancialmente”. Antes de dar comienzo al primer recuerdo ("Mi primer dolor”), introduce una copia de su partida de bautismo que certifica que nació en Filandia el 15 de mayo de 1893 y se le puso el nombre de Ignacio Antonio Torres, el mismo de su padre. La copia mecanografiada es de 1950, año en que acaba de escribir sus reminiscencias, y está firmada por el propio Ignacio. Pero no es la única firma autógrafa que aparece a lo largo del original. Al término de cada uno de los capítulos, siete en total, también estampa su firma. Torres Giraldo muere en Cali en el año de 1968, sólo tres años

6 Pedro María Torres. Diario personal (Inédito), 243. Agradezco a Jorge Hincapié Orozco, egresado por el Programa de Historia de la Universidad del Valle, el conocimiento de esta fuente. Es la base documental a partir de la cual realizó su monografía de grado titulada “El diario del obrero Pedro María Torres, 1940-1992. Análisis contextual de su escritura autobiográfica” (Tesis de pregrado, Universidad del Valle, 2016).

7 Ignacio Torres Giraldo, “Situación del escritor”. FITG, 3/6-A, s.d., 1. 
después de que se pusiera a revisar estos recuerdos pensando en su posible publicación futura: "en caso de ser publicados les haría una breve introducción para dedicarlos a mis hijos Eddy y Urania”" La inclusión de la copia de la partida de bautismo y las firmas autógrafas con que cierra cada uno de los recuerdos intentan otorgar un carácter de oficialidad, de veracidad a su escritura y a su autoría. Es el propio Torres Giraldo el autor de estas páginas, el mismo que nació en el lugar y la fecha certificados y es él mismo quien certifica con su firma la autoría personal de lo escrito. De esta manera está dando fe a quien en el futuro pueda leer estas hojas mecanografiadas a tinta negra, de su autenticidad, de la autenticidad de su encuentro o su hallazgo.

Ignacio Torres Giraldo manifiesta en repetidas ocasiones una preocupación por su escritura, por todo lo que tiene escrito y pueda un día darse a conocer por medio de su edición, la manifiesta en repetidas ocasiones. Dos de ellas son significativas. En cuatro cuartillas sin fecha, posiblemente próximas a su muerte, habla de los "proyectos de libros que deseo escribir tan pronto como tenga el tiempo y la relativa tranquilidad que tal empeño exige”. En ellas aparecen cuatro títulos de libros con su estructura ya pensada, donde se relaciona el enunciado de sus correspondientes capítulos. Son libros que titula Experiencias de algunas huelgas en Colombia, con XI capítulos; Jorge Eliécer Gaitán y su época (XIV capítulos); Primer ensayo de un partido de masas en Colombia (XV) y Mi actuación como miembro de la Internacional comunista $(\mathrm{XV})^{9}$.

De 1962 es su escrito titulado "Por si la muerte me toma sorpresivamente”. En él hace referencia a la mencionada copia de su partida de bautismo, relaciona el nombre de algunos de sus familiares y médicos, con sus respectivas direcciones; y de la misma manera acompaña un listado de sus amigos en Medellín, Envigado, Cali, Cartago y Bogotá. Con un espacio en blanco para su firma, deja otro para finalizar así: "Dejo los originales y propiedad de mis libros, archivos y pequeñas pertenecías a Como no tengo creencias religiosas, pido que se obre consecuentemente" ${ }^{10}$.

La escritura autobiográfica de Ignacio Torres Giraldo no registra, como los diarios, el día a día del sujeto escribiente, pero estos episodios de recreación memorística ofrecen información, datos, señalan acontecimientos de fecha concreta y a base de ramalazos reflexivos, su autor no sólo se recuerda reviviéndose, también se inscribe en la oficialidad de la historia para textualizarse en la duración. El Archivo Personal del líder político y sindical es una muestra palpable de la abundancia de escritura personal que en él reposa. A su obra histórica, ensayística y literaria, se suma una gran cantidad de "notas", “comunicados", "declaraciones", “conferencias”, "escritos", "informes", "programas" y "correspondencia”; la correspondencia que contiene su archivo (ahora denominado Fondo Doc-

8 Ignacio Torres Giraldo, "Original de Recuerdos de infancia” [1946-1962], 32. FITG, 4/8-A.

9 FITG, 2/8-C. Sólo se cita aquí el título de los textos proyectados, no el de los capítulos.

10 Ignacio Torres Giraldo, "Por si la muerte me toma sorpresivamente”, 1962, FITG, 2/7-C. 
umental Ignacio Torres Giraldo) y la copiosa correspondencia, todavía desconocida, que custodian privadamente amigos y familiares. Se trata de textos en letra manuscrita, en letra mecanografiada por su Remington Rand y en letra de imprenta manejada por el propio autor, que representan la importancia que para él tenía la actividad letrada: “yo que tanto había pensado en el prodigio que para mí representaba el hecho de que las gentes pudieran leer y escribir" 11.

Los emocionantes recuerdos titulados "Cómo aprendí a leer" y "El camino de mis ideas", y algunas de sus anécdotas nos van a hablar de su práctica lectora y escritora, manuscrita, mecanografiada y tipográfica. En Pereira, los abuelos maternos de Ignacio, compraron a su hermana Ester Torres, cuando ésta sólo tenía tres años, "pizarra, citolegia y catecismo"12. Cuando cumplió cinco años, la llevaron a una escuela privada y después de estudiar dos años en ella, se retiraron a la finca de Huertas, donde vivían, pues ésta necesitaba reconstruirse. Como en la zona no había escuela, Ester "organizó un juego" en el secadero del café. El juego consistía en que ella hacía de maestra enseñando el catecismo y las primeras letras a los niños de la vecindad que acudían a la finca. Por iniciativa de los padres de los aprendices, éstos comenzaron a pagar matrícula de 25 centavos al mes a la maestra, con lo que pudo comprar "tablerito" y arreglar "dos tablas sobre cajones para sentar a los niños". La informal escuela ("un caedizo en puro suelo de tierra, pero limpio y de buena luz natural") llegó a contar con más de veinte niños y niñas, entre los que se encontraban “dos grandulazos que caminan más de una legua para venir a las clases" 13 .

Era el año de 1903, Ignacio contaba con 10 años de edad; "el país había cambiado un poco, las gentes del pueblo habían encontrado algún sitio para vivir, el dolor de la guerra [de 1899] estaba pasando" y fue entonces cuando comenzó a aprender a leer, con su hermana la "maestrica" y en el libro de oraciones de la abuela, "que tenía letras grandes" y se titulaba Oraciones al pie del altar, un texto útil para la celebración de la misa tradicional. Uno de sus tíos contaba con un negocio de cacharrería y el sobrino se haría cacharrero si “aprendía a leer de corrido, sobre todo letra de carta”, y si aprendía a conocer los números. La propuesta entusiasmó tanto a Ignacio que tres meses después dejó de cosechar café para hacerse cacharrero: "sabía juntar letras, hacer palabras de memoria, conocía los números y, claro, me sabía casi todo el catecismo de memoria. Lo demás lo aprendí leyendo avisos de "za-pa-te-rí-a”, "es-tan-co", "pe-se-bre-ra”, "pren-de-rí-a”, "ga-lle-ra” y otros que se veían en las tablas

\footnotetext{
11 Ignacio Torres Giraldo, Original de Recuerdos de infancia, 24. FITG, 4/8-A.

12 La citolegia era un método de lectura práctica sin deletrear para uso de las escuelas primarias. Además incluía nociones religiosas, máximas morales, reglas de conducta e higiene, y definiciones de aritmética y metrología.

13 Todas las citas referidas a estos aspectos de lectura y escritura están tomadas del original mecanografiado de Recuerdos de infancia (FITG, 4/8-A); y de algunas anécdotas que recoge su Anecdotario, publicado por la Universidad del Valle (Cali) en el año 2004. El original de esta última obra, también consultado, se conserva en FITG, 6/4-A. Sólo cuando la cita es extensa indicamos el apartado correspondiente de cada una de estas obras entre paréntesis.
} 
voladas de las calles de Pereira, Santa Rosa, San Francisco y Manizales, y sobre todo leyendo las facturas de mis compras y los chistes ilustrados del Almanaque Bristol, que me regalaban por docenas en las droguerías Central y Andina” (Recuerdos de infancia. Cómo aprendí a leer).

La lectura de los autodidactas, como ha observado con exactitud Martyn Lyons solía ser una lectura concentrada, una lectura, en muchos sentidos, "intensiva", basada en la repetición, la recitación y la declamación, que servían de apoyo a la memorización ${ }^{14}$. Oraciones al pie del altar era un texto cuya finalidad lo dirigía a cumplir con estas características lectoras señaladas que propiciaban la lectura en voz alta, la lectura de orador. Los autodidactas, desde los momentos iniciales de su aprendizaje, solían leer de un modo repetitivo, frecuentemente releyendo los pocos textos que tenían a su disposición, ejercitando así la capacidad de su memoria, de la que a menudo, como hace Torres Giraldo, hablan: "sabía casi todo el catecismo de memoria". La lectura popular religiosa para la cual la oralización en voz alta, de la que más tarde el líder sindical mostrará dotes para su puesta en práctica, era un método de aprendizaje en los niños que facilitaba la retención de su mensaje.

Torres Giraldo se fue haciendo lector habitual de periódicos y libros y a medida que iba poniendo más apego a ellos, "el espíritu comercial se fue apagando" en él. El año de 1911, ya con 18 años de edad, fue decisivo en su vida y a partir de ahí comienza su formación ideológica, que tendrá como base lecturas de literatura y filosofía. Es entonces cuando conoce al coronel veterano Germán Uribe Zuleta, quien ejercía de sastre en Pereira y era fanático partidario de Rafael Uribe Uribe. En su taller tenía lugar una tertulia que también dedicaba sesiones a las logias masónicas, a las investigaciones espiritas, a las corrientes librepensadoras, a la internacional de los jesuitas, a la filosofía de artesano de Herbert Spencer y a las de Kant y Baruch Spinoza.

De esta tertulia formaba parte el obrero Pablo Rivas, quien influyó ideológicamente en quien todavía ejercía de cacharrero y se inclinaba ya por el estudio de la "cuestión social” al leer a políticos e intelectuales franceses de corte socialista como Pierre-Joseph Proudhon, Charles Fourier y Jean Jaurès. En la tertulia, que no se reunía de manera regular ni tampoco era homogénea políticamente, Torres Giraldo, dice, participaba poco, pero en ella se vio notablemente estimulado a la lectura en esas conversaciones que recrea con satisfacción:

El coronel Duque se reía del socialismo porque, según él, eso había fracasado desde los decretos-leyes del canciller Bismarck contra los socialistas alemanes y, además, porque dentro del liberalismo cabía todo. El abogado Marín me decía, luego de alabar un poco la sabiduría de La Enciclopedia Inglesa, que teníamos mucho por aprender, pero que de todos

14 Martyn Lyons “Los nuevos lectores del siglo XIX: mujeres, niños, obreros”, en Historia de la lectura en el mundo occidental, edit. Guglielmo Cavallo y Roger Chartier (Madrid: Taurus, 2004), 583. 
modos ya empezábamos a ver el mundo que habitamos (el abogado Marín hablaba con frecuencia de la pluralidad de los mundos habitados, como algo para él evidente), la vida humana y las leyes que la rigen, sin ayuda de magia ni el recurso de los milagros. (Recuerdos de infancia. El camino de mis ideas).

Comenzó así a leer "libros serios" en la biblioteca de alquiler de la Plaza Mayor que regentaba Clotario Sánchez y a comprar obras como el Diccionario Filosófico en seis tomos de Voltaire, donde aprendió a "leer pensando", un hecho que marca diferencias con etapas anteriores de su aprendizaje lector. A Voltaire le sucedieron las “Oraciones” de Cicerón, Lacordaire, Bossuet, Balmes y Rabelais, "pero me quedé un poco volteriano, hasta que pude hacerme un marxista que guía el espíritu de Lenin y el pensamiento de Stalin”. El primer contacto con Marx lo tiene entre 1918 y 1919, en Popayán. Gracias al poeta Guillermo Valencia, pudo leer el resumen de El Capital hecho por Gabriel Deville. Había leído algunos textos de Schiller, de Heine, Nietzsche, Goethe, y la biblioteca de Valencia le "surtía de selectas lecturas", entre ellas El origen de la familia, la propiedad privada y el Estado, de Federico Engels ${ }^{15}$. La búsqueda de este saber libresco fue decisiva para su emancipación intelectual, fundamento de su activismo político y su desarrollo moral y racional.

Los recuerdos autobiográficos son un indicio claro de una mayor conciencia de sí mismo y del manejo de la palabra escrita de alguien con orígenes humildes que no podía beneficiarse de la ayuda de un tutor o un guía, ni de una formación académica regular. Sólo en condición de oyente asistió entre 1912 y 1913 al colegio público Arcadio Herrera de Pereira, a unas clases de gramática del profesor Deogracias Cardona; y entre 1921 y 1922, a unas cátedras de bachillerato dictadas en la Universidad del Cauca de Popayán.

Torres Giraldo relata los hechos y esfuerzos que le conducen al éxito de poder dominar la palabra escrita y la palabra oral ("las gentes me siguieron tomando en serio como orador") con las que pudo llegar a ser un reconocido sindicalista y periodista. Entre el año de 1940, cuando comienza a escribir sus "recuerdos", y fines de la década de los años cincuenta, cuando acaba sus "anécdotas", siente la evolución positiva que se ha experimentado en su trayectoria formativa hacia, como decía, la "madurez ideológica” y, con ella, la madurez como escritor que le permiten alcanzar la emancipación individual con pretensiones de hacerla colectiva. Fue un autodidacta comprometido que reconoció la importancia de la palabra escrita para elaborar y difundir la ideología política de la clase obrera. Como autodidacta se sometió al deseo, casi obsesivo, de formarse por medio de la lectura y mejorar

15 Ignacio Torres Giraldo, Cincuenta meses en Moscú (Cali: Programa Editorial de la Universidad del Valle, 2005), 10. En 1935, Valencia en su periódico Claridad escribía que había prestado la obra completa de El Capital de Marx a artesanos que no la conocían. Ignacio Torres Giraldo, Anecdotario. La biblioteca del poeta. 
su producción escrita. Una obsesión lógica si tenemos en cuenta su necesidad inmediata de ganarse la vida, de superar los obstáculos materiales que le separaban de sus objetivos de progreso. Como artesano o vendedor ambulante que fue en sus inicios laborales, hay que suponer que sus ritmos de trabajo fueron irregulares y los periodos de inactividad laboral posibilitarían sus esfuerzos por formarse.

\section{La actividad tipográfica}

Leía el periódico El Liberal, de Rafael Uribe, y se convirtió, como dice, en "un liberal libre-pensador con tendencias hacia un socialismo popular" o un "revolucionario de ideología proletaria". Al poco tiempo de participar en las tertulias de Germán Uribe, en 1912, comenzó a escribir en periódicos de provincia como Albores y El Aguijón. Desde entonces, su actividad en la prensa fue larga y diversa: como escritor, como "colaborador artístico" que elaboraba artesanalmente clisés de madera, como tipógrafo asociado a empresas políticas colectivas, o como director de periódicos.

Por los años de 1914 y 1915, Benjamín Tejada Córdoba, padre del cronista Luis Tejada y rector del Instituto Murillo Toro, fundó en el centro el periódico El Surco, donde Ignacio fue "colaborador artístico" con la producción de sus maderas, grabados (próceres, santos, militares, curas, políticos y personajes de cine mudo) como clisés tipográficos cuya afición practicó entre 1912 y 1917, colaborando en revistas del lugar como la literaria Vendimias que fundó el poeta pereirano Alfonso Mejía Robledo. Grabados en madera que veremos utilizar también en su periódico El Martillo y que resultaban más económicos que el uso de técnicas xilográficas y de fotograbado, demasiado complejas para las limitadas posibilidades de los periódicos populares.

El 15 de octubre de 1916, segundo aniversario de la muerte del general Rafael Uribe, salió a la calle el periódico que dirigió Torres Giraldo, El Martillo. Periódico del Pueblo. A base de suscripciones que el propio Torres distribuía, el semanario publicó 38 ediciones. Su actividad en la prensa, bien colaborando como escritor, bien en funciones tipográficas como asociado o director de la edición de algunos impresos, fue fecunda. Desde el siglo XIX, todavía el periódico siguió ejerciendo de actor político y ahora, en la primera mitad del XX, se le sumó la actividad sindical. Los periódicos generaban hechos políticos, laborales, tramas, alianzas, rupturas que, generalmente a iniciativa particular, contaron con comunidades de lectores y crearon o reforzaron su identidad política, muchas veces formando redes de relaciones sociales que se afianzaban alrededor de intereses comunes. A los periódicos, en esta época había que añadir la producción tipográfica de propaganda política: “No somos enemigos de la propaganda escrita", del "escrito de agitación”. "Nosotros no oponemos a la propaganda escrita la lucha por las reivindicaciones inmediatas", "estamos de acuerdo con el empleo 
de material escrito (en papel, en la pared con una consigna o un alerta, etc.) si estas son las formas habituales empleadas por los obreros"16.

En Cali, a fines de 1917, fundó el malogrado periódico La Democracia. Se traslada a Popayán “como trabajador aficionado a las letras de imprenta” y en 1918 participa en la organización del Directorio Socialista del Cauca, que un año después funda el periódico La Ola Roja, con pretensiones de extender y popularizar el sistema soviético. La edición de un periódico era una empresa colectiva que solía nuclear a un grupo de personas, quienes se vinculaban a las diferentes actividades relacionadas con la publicación: redacción, composición de textos, manejo de la imprenta, distribución, grupos informales pero organizados que posibilitaban la circulación del periódico. Francisco José Valencia, hermano del poeta Guillermo, y “radical-socialista muy beligerante”, se hizo con una imprenta vieja Washington de brazo sumamente lenta y en la casa del fundidor Enrique Quijano, veterano coronel de la guerra del noventa y nueve, "especie de anarcoliberal bien explosivo", se fundó La Ola Roja. La inconveniente "prensa grande" y vieja funcionó sólo con "tipógrafos amigos", no con operarios de planta. Tuvieron que trabajar muchas veces durante las madrugadas y las deficiencias de infraestructura se vieron aumentadas por la falta de papel de imprenta en Popayán. Tenían que comprar papel de envolver que necesitaba ser humedecido para que "agarrara la tinta”, dificultando la subida de los pliegos al bastidor de la impresora y después al bastidor del molde para preparar "el retiro".

Dedicado a producciones propias, por los años diecinueve y veinte, publicó en Popayán dos folletos de rueda suelta. Editados por una pequeña imprenta que produjo "horribles errores", uno de ellos lo tituló Prosas Libres y es entonces cuando lee también Democracia burguesa y democracia obrera, de Lenin. En 1923 se traslada a Cali y en ese mismo año la organización de trabajadores de ferroviarios del Pacífico y obreros de la construcción, llamada “Alarifes y Similares", fundó El Obrero del Valle, un semanario liberal radical, por lo que pronto las imprentas se negaron a editarlo. Por medio de gestiones del propio Torres Giraldo, los protestantes, que operaban en la Tipografía Aurora, cerca de la plaza de San Nicolás (barrio caleño que todavía mantiene su tradición tipográfica), pudieron tirar El Obrero del Valle los sábados y, a fin de cada mes, El Mensajero Evangélico.

Después de la explosión política del Primero de Mayo de 1925 y la suspensión definitiva de El Obrero del Valle, Torres Giraldo compró una “vieja imprenta” en la población de Zarzal por 250 pesos y la trasladó a Cali. Completó el equipo con una prensa de mano marca Washington que costó 100 pesos y trajo de Pereira, más unos accesorios de 150 pesos. Con todo ello, a mitad de mayo pudo salir un nuevo periódico de los trabajadores del Valle, La Humanidad, título copiado de un periódico fun-

16 Ignacio Torres Giraldo, "Errores de método de trabajo o El mal llamado asunto de la propaganda escrita (Por Mara)", s.d., FITG, 3/5-C.,2-3. 
dado por Jean Jaurés, órgano del Comité Central del Partido Comunista de Francia. La Humanidad llegó a ser el órgano de la CON (Confederación Obrera Nacional), pues Cali fue elegida la primera ciudad como sede de esta Confederación y Torres Giraldo fue nombrado secretario general de la misma. Con un formato de un octavo de pliego y ocho páginas, las primeras ediciones se hicieron en una "prensita de octavo movida a pedal". En La Humanidad, que funcionó alrededor de "procomunistas con denominación abierta de socialistas revolucionarios desde fines de 1926”, publicaron escritores aprendices, iniciados en cuestiones ideológicas. El periódico progresó, dotándolo de maquinaria nueva que permitió darle una aceptable presentación en 1928, cuando pretendió aparecer diariamente y dejó de editarse.

La diversidad de periódicos donde participa Torres Giraldo será una prueba más de que la estructura social colombiana estaba cambiando y había un sector social en ascenso que era el de los trabajadores asalariados que pugnaban por un lugar dentro de la nación. Las organizaciones políticas y sindicales de tinte iluminista (marxismo, anarquismo, liberalismo, socialismo, radicalismo) deseaban ampliar la cultura escrita entre las clases populares y para ello el periódico, el folleto y la hoja suelta que editaban y podía circular fácilmente de mano en mano, entre bibliotecas obreras, sedes sindicales o imprentas, debía ser un elemento de pedagogía de democratización cultural y reivindicaciones sociales, central de la identidad y la cotidianidad de las personas que, como decía El Martillo en su número 2 del 21 de octubre de 1916, debían “andar con la sonrisa en los labios y el periódico en el bolsillo". Este tipo de impresos y especialmente los periódicos, no respondían exclusivamente a estrategias de reclamaciones políticas o económicas. Sobre la base de una "voluntad de representación" de los sectores obreros y populares, acogían objetivos diversos: "el avance de la razón y la verdad, la educación del pueblo, su elevación material y moral, el mejoramiento de sus condiciones de existencia, la libertad de expresión y asociación, y la participación política”17.

A mitad de la década del 30, Torres Giraldo todavía dirigía el periódico Tierra. Desde 1912 escribió casi continuamente en periódicos obreros y durante 1944-1945 fue colaborador de la conocida revista Temas que se editaba en Medellín. Fue buen conocedor de periódicos que nacieron al calor de pequeñas agrupaciones políticas o sindicales; al calor de la amistad en reducidas poblaciones, como así nació y por un tiempo vivió El Tribuno, de Pradera (Valle) por los años de 1923 y 1924; y como así, concluyendo con la "extraordinaria capacidad de iniciativa del pueblo", ocurrió con el caso de Jorge del Bosque, un obrero del alto Magdalena que en el puerto de Beltrán cargaba y descargaba naves y dirigía El Soviet, un periódico revolucionario de idónea presencia que confeccionaba en su

17 Luz Ángela Núñez Espinel, El obrero ilustrado. Prensa obrera y popular en Colombia, 1909-1929 (Bogotá: Universidad de los Andes/ Facultad de Ciencias Sociales-Ceso/ Departamento de Historia, 2006), XXI, XXIX, 29, 79. 
casa, "un tugurio que había construido con desperdicios de cajones, a cuya entrada mariposeaba una banderita roja”.

Torres Giraldo desarrolla una escritura tipográfica de inmediata aparición pública, política, sindical, junto a una escritura manuscrita más doméstica o íntima y una escritura mecanografiada con la que encontramos la mayor parte de su producción intelectual y literaria, que construye, según dice, como habla, pero poniendo en práctica un determinado método de trabajo: "Yo tomo apuntes en papelitos, copio citas y cifras, todo a mano, reviso en lo posible mis archivos y extraigo de ellos lo que pueda servirme, según el tema; después clasifico estas cosas por materias y teniendo a la mano un mapa de Colombia y un diccionario popular como el Vastus de Sopena, me siento ante una máquina y escribo, despacio, muy despacio, leyendo cada párrafo, controlando bien la claridad de las ideas, y en general desechando adjetivos decorativos, palabras sobrantes, expresiones plebeyas y giros de pedantería. Escribo a renglón cerrado, y luego de leer la cuartilla que termino, tiro al margen las correcciones. Y ya está." (Anecdotario: Mi modo de escribir).

\section{La escritura autobiográfica: un aprendizaje del contacto humano}

Si en el vivir de hoy la esencia de nuestra manera de ser que se comunica en el trato público es lo menos propio, lo menos personal que hay en cada uno de nosotros, cuando a través de su Anecdotario sabemos de las abundantes y diversas relaciones que llegó a tener Torres Giraldo, encontramos a un hombre que durante la primera mitad del siglo XX colombiano, un tiempo bien distinto al de ahora, construyó una personalidad marcada por un halo de respeto y autenticidad. Una personalidad tal vez ayudada por la facilidad de palabra, tanto en la conversación directa como en el ejercicio de la oratoria, y esa cualidad de ser, como dijo el traductor de su estancia en Moscú, "un creador popular que oía los pensamientos de las gentes y sabía entrar a la morada de sus ideas”. Respeto y, al leer algunas cartas personales, podríamos añadir, "amabilidad”. Torres Giraldo escribió con regularidad numerosas cartas a muchos de sus familiares siempre con un trato respetuoso, de "rigurosa caballerosidad", como diría su hija Urania. Además de las preocupaciones sobre el tema laboral y la salud, acostumbradas a incluirse en la correspondencia familiar, era habitual en él hablar, con responsabilidad, de la educación dirigida a "formar hijos [...] en un ambiente no sólo sano, amable, de confianza y cariño en el hogar, sino también de estudio, de reflexión, de amenidad y buen humor y seriedad. Seriedad en el sentido de que no se hagan frívolos, superficiales, negligentes, irresponsables. Para esto es indispensable que empiece a sentir placer en las buenas lecturas, que se sientan orgullosos de poder expresar sus pensamientos escribiendo por afición"18.

18 Carta de ITG fechada en Medellín el 13 de marzo de 1961 dirigida “A la señora Urania Torres de Rodríguez”, en Sevilla-Valle”). 
Cuando tratamos con un juez funcionario del Estado ya no somos nosotros, sino unos ciudadanos cualesquiera, y ese hombre, ya no es Juan o Pedro, sino pura y simplemente el Estado. En estas circunstancias, nuestra peculiar, inconfundible, única personalidad permanece oculta en la relación pública. Sin embargo, Torres Giraldo describe momentos de su vida donde sus acciones y reacciones -probablemente envueltas ahora en su escritura por la nostalgia del recuerdo que concede un mayor decoro humanitario-, no son mecánicas ni externas, no están fijadas en la definición misma de esas "especies" o clasificaciones sociales que son el funcionario, el profesional y el ciudadano. En las relaciones públicas que aparecen a lo largo de Recuerdos de infancia y Anecdotario, sobresale la vida humana del autor que entra en contacto con la gente para hacer de ese contacto no una relación abstracta, convencional o anónima, sino una relación en la que prima la naturaleza humana, muchas veces ante situaciones de "atropello" social que se estaban dando en Colombia. Veamos una de esas situaciones que le ocurrió en la cárcel de Medellín, después de escribir una breve novela, todavía inédita, en la cárcel de Manizales.

Desde 1926 hasta mediados de 1929, durante varias temporadas, Torres Giraldo habitó diferentes prisiones. Antes de pasar a la cárcel de Medellín, estuvo en la de Manizales. Aquí, a mediados de 1928, sobre un papel rosado en formato de pequeño libro (hojas de $37 \mathrm{~cm}$. x $24 \mathrm{~cm}$. dobladas por su mitad haciendo cuadernillos de 4 páginas de $18 ’ 5 \mathrm{~cm}$. x $12 \mathrm{~cm}$.) escribió, según él mismo la califica, una "novelita romántica, casi ingenua”, que tituló Fuga de sombras. En 1956, después de revisar su “viejo y desordenado archivo" y hallarse con estos originales y descoloridos papeles, donde a lápiz hizo "una primera corrección”, en previsión de una futura publicación, decidió escribir un prólogo a la novelita que tituló "Tres peldaños de una vida”. Es en este prólogo donde nos dice que Fuga de sombras fue escrita en una etapa de su vida que podría caracterizarse por una "tendencia a teorizar sobre problemas sociales" y a "insinuar soluciones inconexas y parciales, a la manera de los idealistas, sobre todo de concepciones anarquistas".

En 1956, en una etapa ya de "maduración ideológica”, al descubrir este que llama "ensayo de novela”, pensó en destruirlo, pero sólo hizo correcciones para suprimir, cambiar o agregar palabras:

no tacho [...] la sensibilidad, la humana embriaguez de la carne encendida por la pasión, la mística adoración del enamorado primerizo, tímido por naturaleza y además anudado a herencias dogmáticas de moral a la española. En general no tacho en ella nada porque es trasunto de realidad, de la vida elemental. Me disuena esa literatura de fronda que allí campea, ese lirismo seguramente petulante de aprendiz de prosa [...] algunos giros y palabras, 
comunes pero ajenos a la estructura actual de mis ideas [...] algunos recursos de ficción empleados entre ajustes. Sin embargo, de todo ello debo confortarme si pienso que he logrado superarme, en mi modesta condición de escritor proletario ${ }^{19}$.

Dejando a un lado la calidad literaria, hace que primen otros motivos sobre ella y defiende así la conservación de la novela que quiere ser al mismo tiempo autojustificación de perdurar en el tiempo mediante la no destrucción de su escritura. El ejercicio escriturario se ha hecho cotidiano desde hace muchos años y, en tanto es continuamente pensado, se convierte en obsesión. Expurgar lo que un día construyó la escritura es evaporar parte de su vida.

Fuga de sombras "es un producto de la cárcel, del aislamiento, de la soledad", de una "voluntad quebradiza" que todavía no tiene una "estructura ideológica [...] bien forjada", de ratos de "obscuridad mental, de confusión, de ira y de dolor", aunque Torres Giraldo no era en 1928 un primerizo del cautiverio: "ya había estado en una celda de la prisión de Tunja, en un torturante calabozo en Cali, en La Dorada en Armenia. Sin embargo, mi primera temporada de recluso en Manizales se hacía larga; se me tenía separado de los otros presos, con centinela de vista en el día y doble cerrojo en la noche. No se me permitía leer periódicos, y los pocos libros que la dirección penal me procuraba, eran por lo común, vidas de pecadores arrepentidos y de santos martirizados"20.

Luego, pasando por la población de La Ceja y en calidad de preso, Torres Giraldo, es llevado desde Manizales a la cárcel de Medellín, donde ya en 1929 pasa otra temporada, y escribe la obra de ficción cuyos originales se perdieron, titulada La estirpe (o El hijo de Margarita), uno de los personajes este último que, idealizado, aparece en la novela Fuga de sombras. En uno de esos momentos diarios en que el juez pasa lista en la prisión de Medellín, éste preguntó si alguien deseaba hacer algún tipo de reclamo. El autor levantó entonces su voz para denunciar la situación de quienes se encontraban presos sin ser todavía juzgados, y proponer a la vez la creación de talleres de trabajo y de lectura ante las degradantes consecuencias del ocio generalizado que existía entre los reclusos. Estos, dice el autor, estallaron en frenéticos aplausos: "El alto juez me contestó con mucha cortesía, ofreciéndome estudiar los problemas planteados en mi intervención; me felicitó por la 'redentora idea de hacer de la cárcel un lugar de trabajo'. La visita judicial terminó. Los jueces pasaron por calle de honor que se les hizo, algunos me estrecharon la mano" (Anecdotario: En la cárcel de Medellín)²1.

19 Ignacio Torres Giraldo, “Tres peldaños de una vida”. Medellín, agosto de 1956, p. 3. Prólogo que acompaña a la novela original Fuga de sombras, escrita bajo el seudónimo Iván Alín. Manizales, 1928. FITG, 4/2-A.

20 Ignacio Torres Giraldo, "Tres peldaños de una vida”. p. 3.

21 El escrito impreso titulado Inquisición policiva (FITG, 3/5-A), fechado en la cárcel de Manizales el 12 de julio de 1928, es buena muestra del estilo con que Torres Giraldo se defendía cuando estaba en prisión. El escrito, dirigido al Presidente de la Cámara de Representantes muestra también la manera como actuaban las autoridades. En la ciudad de Armenia, el 27 de abril de 1928, el líder sindical es llevado a prisión después de haberle requisado su equipaje, donde llevaba libros, folletos, periódicos, facturas, notas, 
El sentido social de este momento es ejemplo del tono que recorre la mayoría de estos recuerdos y anécdotas que el propio autor ha tenido que extraer y seleccionar del arca de su memoria. Por debajo de lo anecdótico, de estos sucesos circunstanciales y aparentemente irrelevantes donde se describen hechos y vidas reales de personas verdaderas que se narran con pretendida sencillez, subyace lo colectivo, lo social, lo profesional y lo político, lo que ha moldeado la auténtica personalidad, vista ahora desde un yo íntimo que siente y quiere.

Conocer es saber lo que algo es. Más allá de las cosas, Torres Giraldo se interesó por el conocimiento de las personas. Los hechos, una vez transcurridos, como las cosas, permanecen quietos y pasivos, mientras que las personas contienen un último residuo activo en cuyo trato hay necesariamente implicada una reciprocidad. Conocer significa en realidad conocerse mutuamente. La cosa es objeto y la persona subjetividad. La historia, como se dice en Los inconformes, es mucho más que los hechos en sí, más que los factores que hacen posible los hechos. Como las personas, la historia, más que objetividad es también esencia subjetiva. Observando bien los pequeños procesos vivenciales de la gente, las decisiones o actitudes, es posible develar, bajo el manto de la "ingenuidad" o el estilo de la "torpeza", el sentido de la "picardía”. Torres Giraldo aprende del contacto humano ("en el trato menudito con las gentes he aprendido a distinguir estas cosas que a veces se parecen entre sí”) para visualizar y proyectar el desarrollo histórico de la sociedad como una realidad que requiere saber qué impulsos la han formado. Frente al intelectual tradicional, "aristócrata y feudal", que vive arrinconado en sus bibliotecas, soñando en el "mundo maravilloso de los libros", el autor defiende al "hombre público que evoluciona con el proceso histórico de los pueblos y sabe percibir las pulsaciones que anuncian los grandes cambios de la Humanidad"22.

\section{Conclusiones}

El sentido común o saber popular, sostiene Fals Borda, es útil como fundamento de la acción social $^{23}$. La relación de Ignacio Torres Giraldo con la experiencia popular de base obrera, campesina e indígena; y con la experiencia participativa de organismos gremiales y políticos, le sirven a su faceta

papeles de negocios y relaciones personales. En la diligencia indagatoria del proceso judicial que se le hizo, Torres Giraldo protestó por "adulteraciones, falsas y torcidas interpretaciones de que se hizo objeto algunos de mis papeles, después de que a estos se agregó un anónimo bélicamente tendencioso y a un mapa oficial se le puso una napoleónica leyenda de sabor torturante de campaña, absurda e infame".

22 Ignacio Torres Giraldo, "El intelectual y el hombre público en Colombia”. s.d., p.1. FITG, 3/5-H.

23 Orlando Fals Borda, El problema de cómo investigar la realidad para transformarla por la praxis (Bogotá: Tercer Mundo Editores, 1997), 19. Sobre la propuesta del método de investigación cualitativo que denomina "investigación-acción participativa”, basado en el estudio de las relaciones recíprocas entre sentido común, ciencia, comunicación y acción política; interpretando la realidad desde el punto de vista proletario y estudiando cómo se combinan sujeto y objeto en la práctica de la investigación, véase páginas 11-57. 
de investigador, que implica una inserción en el proceso social y una subordinación a la práctica política. Torres Giraldo produce conocimiento a partir de la realidad inspirada en los intereses de las clases trabajadoras, un conocimiento que quiere ser relevante para la práctica social y necesario para la experiencia pedagógica política.

En la primera mitad de los años setenta del siglo XX, de acuerdo a conveniencias y objetivos de los grupos de base, se editaron libros como los de Orlando Fals Borda (Historia de la cuestión agraria en Colombia, 1975 y Modos de producción y formaciones sociales en la Costa Atlántica, 1974), el de Manuel Quintín Lame (En defensa de mi raza, 1972) y los de Ignacio Torres Giraldo (María Cano, mujer rebelde, 1973 y La cuestión indígena en Colombia, 1975). Como en la descripción de sus episodios autobiográficos, basados en experiencias cotidianas, con el método “investigación-acción” que proponen obras como las que se acaban de citar, Torres Giraldo trata de conocer y apreciar el papel social que juega la cultura del pueblo a través del contacto personal y humano con ella, para obtener y crear conocimiento científico.

El centro de su obra autobiográfica se constituye de momentos personales seleccionados arbitrariamente por quien los rememora. Indudablemente su esencia protagónica es inseparable al discurrir de su escritura, pero bajo ella subyace otro tipo de escritura que funciona como guía y objetivo mayor de toda su obra, la escritura de quien trabaja para armar ideológica e intelectualmente a los sectores populares y estos puedan asumir conscientemente su papel como actores de la historia. No es necesario decirlo, con un talante, como lo define su nieto José Eddy Torres, de "gentleman socialista", Torres Giraldo asumió durante toda su vida ese papel, y desde él, es que podemos abrir caminos interpretativos a sus "recuerdos" y "anécdotas".

Hechos, personajes y escenarios múltiples de un solo contexto histórico-social que abarca lo que abarca la vida activa de un relevante político, periodista, historiador y sindicalista colombiano, se presentan en sus pedazos autobiográficos sin fingimientos para romper anonimatos y en lo posible hacer visibles fragmentos de su propia vida y otras vidas minúsculas por lo poco conocidas. Nombres y pequeños sucesos que probablemente no vuelvan a tener oportunidad de aparecer escritos. Nombres de vidas anónimas, pero también nombres de actores conocidos que en la narración más ligada al campo político, no dejan de aparecer por haber mantenido algún tipo de relación (circunstancial, amistosa, familiar, laboral, política, sindical) con el eje central de los recuerdos y las anécdotas: Ignacio Torres Giraldo, contador, en este caso, de pequeñas historias que no arrincona como personajes secundarios a quienes hace aparecer en su narración, por el contrario, los hace relevantes de estos escasos momentos que para él poseen alguna significación personal y política; escasos frente a "Lo que pudo ser y no fue", un título, según él, bajo el cual podría haber escrito muchos episodios de su vida. 


\section{Referencias Bibliográficas}

\section{Fuentes primarias/documentales}

\section{Fuentes manuscritas:}

Torres, Pedro María. Diario personal,1940-1992 (Inédito).

Torres Giraldo, Ignacio. Inquisición policiva, 1928. FITG, 3/5-A.

Torres Giraldo, Ignacio. Tres peldaños de una vida, 1956. Prólogo que acompaña a la novela original Fuga de sombras (1928). FITG, 4/2-A.

Torres Giraldo, Ignacio. "Nota previa” al original de Recuerdos de infancia, 1965. FITG, 4/8-A.

Torres Giraldo, Ignacio. Por si la muerte me toma sorpresivamente, 1962. FITG, 2/7-C.

Torres Giraldo, Ignacio. Errores de método de trabajo o El mal llamado asunto de la propaganda escrita (Por Mara), s.d. FITG, 3/5-C.

Torres Giraldo, Ignacio. El intelectual y el hombre público en Colombia, s.d. FITG, 3/5-H.

Torres Giraldo, Ignacio. Situación del escritor, s.d. FITG, 3/6-A.

Torres Giraldo, Ignacio. Proyectos de libros que deseo escribir, s.d. FITG, 2/8-C.

\section{Fuentes impresas}

\section{Publicaciones periódicas:}

Carranza, María Mercedes. "Guía de libros: Los inconformes”. El Tiempo, Bogotá, 21 de enero, 1974.

\section{Libros:}

Torres Giraldo, Ignacio. Anecdotario. Cali: Programa Editorial de la Universidad del Valle, 2004.

Torres Giraldo, Ignacio. Cincuenta meses en Moscú. Cali: Programa Editorial de la Universidad del Valle, 2005.

Torres Giraldo, Ignacio. Original de Los inconformes, 1955. Tomo II: Las guerras civiles en Colombia como luchas de masa por el predominio de las ideas democrático-liberales. FITG, 6/2-A.

Torres Giraldo, Ignacio. Original de Recuerdos de infancia, 1946-1962. FITG, 4/8-A.

\section{Bibliografía consultada}

De Certeau, Michel. La escritura de la historia. México DF: Universidad Iberoamericana/Instituto Tecnológico y de Estudios superiores de Occidente, 2010.

Fals Borda, Orlando. El problema de cómo investigar la realidad para transformarla por la praxis. Bogotá: Tercer Mundo Editores, 1997.

Hincapié Orozco, Jorge. “El diario del obrero Pedro María Torres, 1940-1992. Análisis contextual de su escritura autobiográfica”. Tesis de pregrado en Historia, Universidad del Valle, 2016.

Lyons, Martyn “Los nuevos lectores del siglo XIX: mujeres, niños, obreros”, en Historia de la lectura en el mundo occidental, edit. Guglielmo Cavallo y Roger Chartier. Madrid: Taurus, 2004.

Núñez Espinel, Luz Ángela. El obrero ilustrado. Prensa obrera y popular en Colombia, 1909-1929. Bogotá: Universidad de los Andes/ Facultad de Ciencias Sociales-Ceso/ Departamento de Historia, 2006. 
Rubio, Alfonso y Viviana Arce. Inventario general. Fondo documental Ignacio Torres Giraldo. Cali: Universidad del Valle, 2014.

Sibilia, Paula. La intimidad como espectáculo. México DF: Fondo de Cultura Económica, 2008. 